\title{
Fast Color Grouping and Slow Color Inhibition: Evidence for Distinct Temporal Windows for Separate Processes in Preview Search
}

\author{
Jason J. Braithwaite, Glyn W. Humphreys, Johan Hulleman, and Derrick G. Watson \\ University of Birmingham
}

\begin{abstract}
The authors report 4 experiments that examined color grouping and negative carryover effects in preview search via a probe detection task (J. J. Braithwaite, G. W. Humphreys, \& J. Hodsoll, 2003). In Experiment 1, there was evidence of a negative color carryover from the preview to new items, using both search and probe detection measures. There was also a negative bias against probes on old items that carried the majority color in the preview. With a short preview duration $(150 \mathrm{~ms})$ carryover effects to new items were greatly reduced, but probe detection remained biased against the majority color in the old items. Experiments 2 and 4 showed that the color bias effects on old items could be reduced when these items had to be prioritized relative to being ignored. Experiment 3 tested and rejected the idea that variations in the probability of whether minority or majority colors were probed were crucial. These results show that the time course of color carryover effects can be separated from effects of early color grouping in the preview display: Color grouping is fast, and inhibitory color carryover effects are slow.
\end{abstract}

Keywords: visual selective attention, attentional guidance, color grouping, inhibition, time effects

Our visual world is complex and dynamic. Many items may simultaneously occupy differing regions of visual space and many items may enter or leave our visual field at any time. However, due to the constraints of needing to direct actions to objects, vision needs to be selective, so that only information that is relevant for current goals is made available to guide behavior. A major issue for vision research is to understand how this selection process takes place over space and time.

One paradigm used extensively to study selection in vision is visual search, in which search efficiency provides a measure of the ease of selection (see Wolfe, 1998, for a review). In the vast majority of cases, visual search studies have assessed the spatial aspects of attention, evaluating, for example, which properties allow targets to pop out in a spatially parallel manner (Treisman \& Gormican, 1988) or how performance varies as a function of the relative eccentricity of the items (e.g., Wolfe, 1998). However, in the real world, search also varies across time as well as space, and our interest may be in selecting stimuli according to the temporal

Editor's Note. Yuhong Jiang served as the action editor for this article.GWH

Jason J. Braithwaite, Glyn W. Humphreys, Johan Hulleman, and Derrick G. Watson, Behavioral Brain Sciences Centre, School of Psychology, University of Birmingham, Birmingham, United Kingdom.

This research was supported by a British Academy Research Fellowship and Roberts Research Fellowship awarded to Jason J. Braithwaite and Biotechnology and Biological Sciences Research Council Grant G9623474 and Medical Research Council Grant BBS/B/16429 awarded to Glyn W. Humphreys.

Correspondence concerning this article should be addressed to Jason J. Braithwaite, Behavioral Brain Sciences Centre, School of Psychology, University of Birmingham, Edgbaston, Birmingham B15 2TT, United Kingdom. E-mail: j.j.braithwaite@bham.ac.uk as well as the spatial group that they belong to. Studies using preview search address the temporal as well as the spatial aspects of visual selection.

In the original study of preview search, Watson and Humphreys (1997) adapted a classic visual search procedure (search for a color-form conjunction; cf. Treisman \& Gelade, 1980) so that observers were given a preview of half of the distractors before being followed by the rest of the distractors and target (when present) after a short duration (typically $1000 \mathrm{~ms}$ ). Under these "preview search" circumstances, performance was greatly improved (relative to a full-set baseline containing a simultaneous presentation of all the items) and is consistent with observers restricting their search to just the new items (containing the target). This improvement in performance has been termed the preview benefit to search (see Watson, Humphreys, \& Olivers, 2003).

Watson and Humphreys (1997) argued that the preview benefit stemmed at least in part from goal-directed suppression of the old items, a process they termed visual marking. This proposal has been corroborated by a number of studies that have set out to measure attentional allocation using probe detection procedures, the notion being that probes should be detected faster when they fall at attended regions, whereas detection should be much slower at unattended regions. A consistent result is that probes are easier to detect on new than old distractors in preview search (Braithwaite, Humphreys, \& Hulleman, 2005; Olivers \& Humphreys, 2003; Watson \& Humphreys, 2000), and probes on old items can be even more difficult to detect than probes in unoccupied (neutral) locations (Agter \& Donk, 2005; Humphreys, Jung-Stalmann, $\&$ Olivers, 2004). It is interesting to note that these effects at the location of probes in preview displays are reduced or even eliminated when the primary task is not to search for a new target but simply to detect the probe (Braithwaite, Humphreys, \& Hulleman, 2005; Humphreys et al., 2004; Watson \& Humphreys, 2000). Thus, the variations in probe detection do not solely reflect the 
temporal parameters of the displays but rather the goal-directed nature of the search task itself (e.g., to prioritize new items or deprioritize old items). Both the preview benefit and the poor detection of probes at the locations of old items are reduced when the preview is exposed for a relatively short duration (Braithwaite, Humphreys, \& Hulleman, 2005; Watson \& Humphreys, 1997), suggesting that any goal-directed suppression has a relatively long time course.

In the original preview study, Watson and Humphreys (1997) suggested that, as a process, visual marking was applied only to the locations of the irrelevant or old items. Since then, however, a number of experiments have shown that the relations between the features of old and new items are also important. For example, the effects of having a singleton color in the new search display are greatly reduced if the singleton has the same color as stimuli in the preview (Braithwaite, Humphreys, \& Hodsoll, 2004; Olivers \& Humphreys, 2003). This can be accounted for by there being a negative carryover effect based on the (suppressed) features of preview stimuli that are currently being ignored. These carryover effects act against the prioritization of new items sharing old, ignored features even if stimuli are singletons in the new display (Braithwaite \& Humphreys, 2003; Braithwaite, et al., 2004; see Olivers, Humphreys \& Braithwaite, 2006, for a review).

\section{Color-Grouping and Carry-Over Effects}

Negative carryover effects, when there are common features in preview and search displays, have also been shown to modulate what we term color-grouping effects in search. Numerous studies using "standard" search conditions, with all the items presented simultaneously, have revealed a bias for observes to direct their search to the smaller of the two color groups (Bacon \& Egeth, 1997; Egeth, Virzi, \& Garbart, 1984; Kaptein, Theeuwes, \& van der Heijiden, 1995; Moore \& Egeth, 1998; Poisson \& Wilkinson, 1992). However, in preview conditions, search for a target in a new minority color group in the search display is greatly slowed if it carries the color of the dominant (majority) group in the preview display. To show this, Braithwaite, et al. (2003) presented search displays with $66 \%$ of the letters in one color (e.g., green) and $33 \%$ in another (e.g., red). These displays were preceded by previews with the opposite color ratios (e.g., $33 \%$ green and $66 \%$ red). Thus, in the final display, both color groups cancelled each other out and were represented equally (50\% red and 50\% green) and targets could occur in either color equally often. In this case, search for targets in the new minority color (red), was inefficient, relative to targets in the new majority color (green). This is despite the fact that color was always irrelevant to the task and was not a useful or informative cue to guide search to the target. The results demonstrate that the preview conditions reverse the standard effects of color grouping on search (i.e., the typical advantage for minority group targets known as the distractor-ratio effect: Bacon \& Egeth, 1997; Egeth et al., 1984; Kaptein et al., 1995; Moore \& Egeth, 1998; Poisson \& Wilkinson, 1992).

The results are consistent with there being greater suppression of the majority relative to the minority color group in the preview display and an associated stronger effect of negative carryover onto targets in the new minority (old majority) condition. The notion that there is greater suppression in the larger group of old distractors fits with arguments put forward by Duncan and Hum- phreys $(1989,1992)$ concerning grouping and selection in visual search. Duncan and Humphreys (1989) proposed that grouped distractors could be rejected from search by a process of spreading suppression, with the strength of any suppression determined by the size of the group.

Braithwaite, Humphreys, and Hulleman (2005) extended the studies of Braithwaite et al. (2003) by incorporating a probe detection procedure along with a manipulation of color grouping in preview search. In doing this they were able to provide a direct measure of any relative suppression of distractors in the old minority and old majority group (in the preview display). Up until that study, all feature-based effects had been assessed indirectly, by the color-based carryover effects on search. As found before, probes were more difficult to detect when they fell on old items relative to when they fell on new, search stimuli (Watson \& Humphreys, 2000). The important new result was that detection was even more difficult if probes fell on preview items in the majority group, relative to when they fell on items in the old minority color. Apparently, spreading suppression was stronger on the old majority group. The carryover of this suppression to the same features in the new search display would generate the negative carryover effects in preview search (Braithwaite \& Humphreys, 2003; Braithwaite et al., 2003, 2004; Braithwaite, Humphreys, \& Hulleman, 2005; Olivers \& Humphreys, 2003).

One other important manipulation in Braithwaite, Humphreys, and Hulleman's (2005) study enabled color-based grouping in the preview display to be separated from color-based carryover to the new search display. In Experiment 4 of the Braithwaite, Humphreys, and Hulleman (2005) study, the colors of the stimuli in the old display changed when the new stimuli appeared. However, the new items could still carry the original colors of the majority or the minority group of old items (which observers had been exposed to during the preview period). Probes on new stimuli were more difficult to detect when the new stimuli carried the color value held by the majority of the old stimuli, compared with when they carried the color value of the minority old group. This demonstrates a negative color carryover effect, based on the color values of the old items (occurring even after the color of the old items had changed). In addition, probes on old items were more difficult to detect when they fell on items that had formerly carried the old majority color, relative to when the old items had formerly carried the minority color. This is interesting because the color values of these stimuli changed between the time of their first presentation and the time when the probes appeared. Hence, the effect on probe detection is unlikely to reflect only suppression of the original color value itself (because following a change of color, these values should not be suppressed); rather, it reflects suppression of the old stimuli within the minority and majority sets originally formed by color grouping. Accordingly, suppression of the old groups can be separated from suppression (and negative carryover) of the feature values that defined those groups originally.

\section{Role of Onsets in Preview Search}

Not all accounts for preview benefits to search subscribe to the notion of inhibition. Some researchers have argued that search is improved under preview conditions because of the new abrupt onset signals from the second search display, which may capture and guide attention to the new target (Donk \& Theeuwes, 2001). 
Donk and Theeuwes (2001) assessed preview search performance when either both the preview and the search display were isoluminant to their background (thus removing all abrupt onset signals) or when onset signals were removed from just the new items. They found that preview search suffered when onset signals were removed from either the whole display or the second search display alone. From this they suggested that onsets were crucial in mediating the preview benefit (see also Belopolsky, Peterson, \& Kramer, 2005; Donk \& Theeuwes, 2003; Peterson, Belopolsky, \& Kramer, 2003).

However, the idea that the preview benefit is due to the automatic capture of attention by abrupt onsets fails to explain several findings in the literature. We consider four points. First, studies using probe detection to assess attentional allocation in preview search show a bias against old locations (Agter \& Donk, 2005; Braithwaite, Humphreys, \& Hulleman, 2005; Humphreys, Jung-Stalmann, \& Olivers, 2004; Watson \& Humphreys, 2000) but only when the probe detection procedure is embedded in a search task. When the main task is probe detection alone, the bias against old locations can be eliminated (Braithwaite, Humphreys, \& Hulleman, 2005; Humphreys et al., 2004; Watson \& Humphreys, 2000). Similarly, preview search is disrupted when a secondary task is introduced during the preview period (Humphreys, Watson, \& Jolicoeur, 2002; Watson \& Humphreys, 1997). The same secondary task presented before the search items has minimal effect on baseline search conditions, in which all the items appear together, suggesting that the secondary task does not interrupt an expectancy for the onset of the search display. Both of these results argue against automatic attention capture by onsets from the search items. Second, as noted above, search for a new item is disrupted if it carries the color of the majority of items in the preview (Braithwaite \& Humphreys, 2003; Braithwaite et al., 2003, 2004; Braithwaite, Humphreys, \& Hulleman, 2005; Olivers \& Humphreys, 2003). If attention capture by the new onsets was sufficient, then the color relations between the new and old items should not matter. However, it is clear that it does.

Third, new onsets are not necessary to generate preview benefits in search. For example, using similar isoluminant displays to those of Donk and Theeuwes (2001), Braithwaite, Humphreys, Watson, and Hulleman (2005) found that preview benefits did indeed emerge when onset signals were removed from the second search display (with the old preview items arriving with an onset allowing for spatial encoding and inhibition of the preview items). This result should not have occurred if the preview benefit is driven solely by onset signals alone. In a further study, Braithwaite, Hulleman, Watson, and Humphreys (2006) demonstrated that a preview benefit could emerge when all the items were isoluminant, provided that the preview was exposed for a longer duration (e.g., $3000 \mathrm{~ms}$ rather than $1000 \mathrm{~ms}$ ). This was not due to simple sensory adaptation under long exposures, because the benefit was eliminated when a secondary task occurred during the preview interval. Preview benefits are not necessarily abolished at isoluminance, but they take longer to emerge. Fourth, sensitivity to new onsets is not sufficient to generate a preview advantage. Following damage to the parietal lobe, patients can be strikingly impaired in preview search (Olivers \& Humphreys, 2003). However, the same patients can continue to show attention capture by new onsets to the same extent as control participants (Humphreys, Olivers, \& Yoon, 2006). Hence, attention capture by new onsets does not necessarily lead to a preview advantage in search. These results indicate that processes additional to automatic capture of attention by onsets play a role in preview search. We suggest that these additional processes involve inhibitory filtering directed towards the old, irrelevant items (cf. Watson \& Humphreys, 1997). Inhibitory filtering may be particularly important when multiple items in the field need to be ignored, when possible capacity limits on attentional capture may also be important (cf. Yantis \& Jones, 1991).

\section{Present Study}

To the best of our knowledge, Braithwaite, Humphreys, and Hulleman's (2005) study provides the first empirical evidence for a distinction between the suppression of color-based groups and suppression based on feature values (the colors) of group members. In the present study we set out to provide a further test of this distinction by evaluating possible differences in the time courses over which the effects occur. We did this in Experiment 1 by varying the interval between the onset of the preview and the occurrence of the search display. Several studies have shown that the preview advantage in search operates over a relatively long time course, so that the advantage is optimized only after previews have appeared for $500 \mathrm{~ms}$ or longer (Watson \& Humphreys, 1997; see Watson et al., 2003, for a review). ${ }^{1}$

Braithwaite et al. (2003) also found that color carryover effects in preview search were reduced when previews appeared only a short time before search displays. This last result, in particular, suggests that color carryover effects may be contingent on a relatively slow-acting process. In contrast, color effects on grouping appear to operate quickly, even with brief displays (see Wolfe, 1998). It may be then that color grouping takes place even on briefly exposed previews, prior to any negative color carryover effects taking place. This would provide further evidence for a distinction between these processes. Effects of both color grouping and color carryover were evaluated using both preview search and probe detection, with the probe detection procedure enabling us to test attentional allocation within old as well as new search displays. A negative color carryover would be demonstrated by both (a) slowed search for targets carrying the majority color of the old display and (b) poor detection of probes on new distractors having the majority color of items in the preview. Color-based grouping would be shown by poor detection of probes on old distractors from the majority color group. Previews were either $150 \mathrm{~ms}$ or $1000 \mathrm{~ms}$. Braithwaite et al. (2003) found color carryover effects to new items with $1000 \mathrm{~ms}$ but not with $150 \mathrm{~ms}$ previews. We asked whether the same temporal constraint holds for grouping between items in the preview (see Figure 1).

In Experiment 2 we asked a second question, which is whether any bias against the majority color in preview displays is relatively

\footnotetext{
${ }^{1}$ Donk and Verburg (2004) have argued that onsets capture attention and some period is then required in order for attention to be released so it can be captured again by the new items. When the first items are isoluminant, old items have little impact even with a short interval between old and (nonisoluminant) new displays. However, isoluminant items have minimal impact on search of nonisoluminant items even when the stimuli appear simultaneously (Braithwaite, Hulleman, Watson, \& Humphreys, 2006). Also, in contrast to Donk and Verburg's proposal, Humphreys, Olivers, and Braithwaite (in press) have shown a long time course to preview search when both the old and new items are defined by color rather than common onsets, contrary to Donk and Verburg's suggestion.
} 


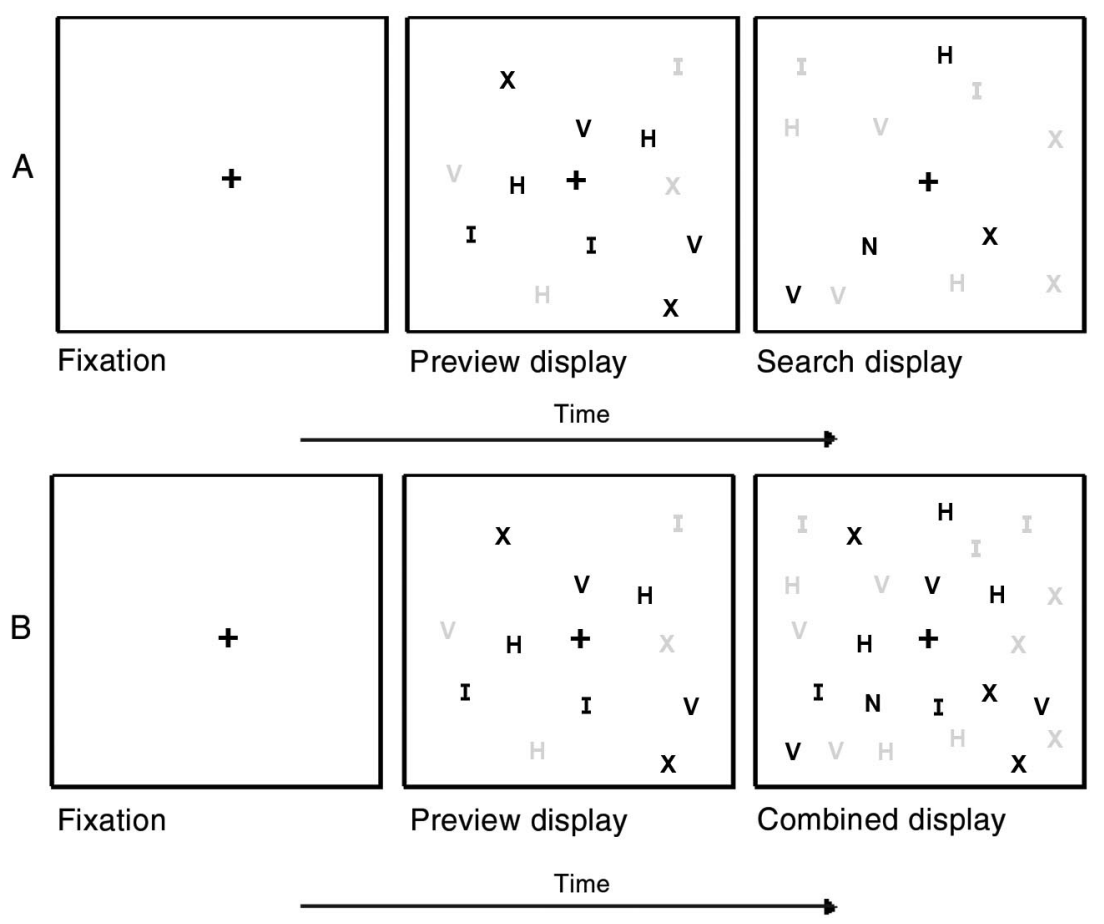

Figure 1. A schematic illustration of a target search trial for the preview color-ratio manipulation used in the current study. A typical trial begins with the presentation of a central fixation cross, followed $1000 \mathrm{~ms}$ later by the preview items. These preview items are color-biased $66 \%$ red (illustrated by the black letters) and $33 \%$ green (illustrated by the light gray letters). The search display had the opposite bias. The top panel (Panel A) shows the opposite color ratios separately for both the preview and search displays (for clarity). The bottom panel (Panel B) shows the same trial but with both displays combined (as it would be in the experiment proper when search was to be initiated). This final overall combined display shows that at the time search was to be initiated there was no overall color ratio. On any given trial the color of the minority and majority sets was counterbalanced so that color or bias could not be used as a reliable cue for search. The figure shows an example target search trial with the target letter being an $N$ in the new minority group (carrying the same color as the old majority). If the trial was a probe trial, then, with the arrival of the second search display, the luminance probe could fall on either group (minority or majority) in either display (preview or search: Experiment 1) or fall on the minority or majority group in the preview display only (Experiments $2 \& 3$ ).

automatic or whether it is dependent upon an attentional set to ignore old items in search. Watson and Humphreys (1997) proposed that visual marking was an intentional, top-down process, determined by the attentional set of the observer. Their argument was based on evidence that secondary tasks, presented during the preview period, disrupt the preview advantage (Humphreys et al., 2002; Olivers \& Humphreys, 2002; Watson \& Humphreys, 1997). This argument is also supported by the finding that the relatively poor detection of probes on old items occurs mainly when probe detection is embedded in preview search and is not solely determined by the displays (Braithwaite, Humphreys, \& Hulleman, 2005; Humphreys et al., 2004; Watson \& Humphreys, 2000). However, this does not mean that the color bias effect is modulated by a set to ignore old items and to prioritize the new. To test this in Experiment 2, we repeated the condition found to elicit a strong bias against old items (preview $1000 \mathrm{~ms}$ ) and contrasted it with a new condition in which participants performed only probe detection (the probe-only condition) and only for probes on old items. If the bias against the majority color is automatic, then the effect should be the same size when participants perform only the probe task and when probe detection is embedded in the search task. Note also that, when probe detection is prioritized, there should be no top-down bias against preview items, as these are now the relevant set for the main task. This condition should remove any inhibitory color-based set directed against those items.

In Experiment 3 we further examined the color grouping effect from Experiment 1 . In Experiment 1 the color-grouping effect was revealed by a contrast between probe detection on old items that carried the majority or the minority color of preview stimuli. In that experiment there were an equal number of trials in which the target fell in the old majority and the old minority groups. However, this also meant that there was an item-by-item probability difference in the likelihood that probes fell on items of different colors. In particular, there were more old items in the old majority relative to the old minority color ( $8 \mathrm{vs} .4$ items), so the probability of a given color being probed was two times larger for an item in the old minority color $(1 / 2 \times 1 / 4=1 / 8)$ than for an item in the old majority color $(1 / 2 \times$ $1 / 8=1 / 16)$. When confronted with a probe display, participants may be biased towards items in the minority color, because these items were twice as likely to carry the probe. Accordingly, slowed re- 
sponses to probes on items in the majority color may be caused by participants being sensitive to these probabilities.

To test this, we varied the probability that probes fell on majority or minority color items in the preview display. We evaluated whether the bias against items in the majority color remained even when there was an equal probability that the probe would fall on any individual majority or minority color item. Across the separate conditions we varied the trial-by-trial ratio in which the target fell in the old majority relative to the old minority group to counteract any item-by-item probability effects guiding search. In three separate blocks, the probability of an old minority item being probed was changed from $1 / 12(1 / 3 \times 1 / 4)$ to $1 / 8(1 / 2 \times 1 / 4)$ and $1 / 6$ $(2 / 3 \times 1 / 4)$. The corresponding probabilities of an old majority item being probed were $1 / 12(2 / 3 \times 1 / 8), 1 / 16(1 / 2 \times 1 / 8)$, and $1 / 24(1 / 3 \times 1 / 8)$, respectively. Note that in the first condition the item-by-item probabilities were equal for stimuli in the old minority and the old majority colors, whereas in the final condition an old minority item was four times more likely to be probed than an old majority item. Thus, we created conditions in which the probes fell in both groups equally often, in the majority group most often, or in the majority group least often. We assessed whether search was sensitive to these differences in the likelihood of where the probe fell.

Finally, Experiment 4 provided a direct within-subjects comparison between crucial preview conditions from Experiments 2 and 3 . Here participants only carried out probe detection trials at both $150 \mathrm{~ms}$ and $1000 \mathrm{~ms}$ preview durations. This isolates, more clearly, pure, fast color-grouping mechanisms from those of colorbased inhibition while the task itself remains the same across both conditions. In the General Discussion we return to evaluate different accounts of preview search in light of the new results.

\section{Experiment 1: The Time Course of Performance}

In Experiment 1 participants carried out preview search on the majority of trials, but on a minority of trials they were cued to detect a luminance probe. In the search task, the target was either a letter $Z$ or $N$, which appeared equally often in either of two colors (red or green). The preview contained letters that were $66 \%$ in one color (the majority) and $33 \%$ in the other (the minority). The search displays contained letters that had the opposite balance of colors to the previews: $33 \%$ in the color of the old majority (the new minority) and $66 \%$ in the color of the old minority (the new majority). Probes could fall on either the old or the new distractor letters. Previews were presented for $150 \mathrm{~ms}$ or $1000 \mathrm{~ms}$ duration.

\section{Method}

Participants. Twenty-six participants (18 female, 8 male; 2 left-handed) took part for course credit or small payment. The age of participants ranged from 18 to 36 years with a mean age of 24.2 years. All were undergraduate or postgraduate students at the University of Birmingham. All had self-reported normal (including normal color vision) or corrected-to-normal vision.

Stimuli and apparatus. All the stimuli and conditions were generated by a series of computer programs written in Turbo Pascal (Version 7, Borland International). The programs were run on a Pentium PC fitted with a 17 -inch super VGA monitor. The programs recorded all relevant key press responses and response times (RTs). This setup was used in all subsequent experiments. The stimuli consisted of colored (red and green) capital letters (with an approximate width of $6 \mathrm{~mm}$ and height of $7 \mathrm{~mm}$ ) displayed on the plain black screen background. The colored letters were randomly assigned to an invisible 48 cell, circular matrix. This virtual matrix consisted of three concentric circular ring grids. The distance from central fixation to the middle of the cells of the first ring measured approximately $19 \mathrm{~mm}$ (containing 8 cells), the second ring $38 \mathrm{~mm}$, (containing 16 cells), and the third $58 \mathrm{~mm}$ (containing 24 cells). Distractors consisted of the upper case letters $H, I, V$, or $X$, and the target letters were either a $Z$ or $N$. Search displays were generated by randomly positioning each letter in the middle of individual matrix cells. Any distractor letter could repeatedly occur in multiple numbers in any display with the restriction that at least one distractor letter of each type was presented. The preview conditions involved the presentation of half (12) the distractor letters first (in the first preview display) followed by the remaining half (12) in the second (search) display. The target was present on every search trial, with it being a $Z$ or $N, 50 \%$ of the time (at random). On probe trials a single probed distractor either underwent a marginal increase in luminance (on old preview items) or was presented in the new set as a marginally brighter item. Pilot baseline studies revealed this increment value to be sufficient for effective detection during standard search conditions but not so salient as to induce large cuing and attentional capture effects.

Design and procedure. A $2 \times 2$ (Condition $\times$ Search Type $)$ within-subjects design was used. The two preview conditions varied just in the preview duration, which was either $150 \mathrm{~ms}$ or $1000 \mathrm{~ms}$. Each condition was run as a separate block of 288 trials. A break was given halfway through each block. Only $33 \%$ of the trials in each condition contained a luminance probe. The remainder of the trials $(66 \%)$ were standard target search trials (either a $Z$ or $N$ ). For search trials there were equal numbers of trials for new minority and new majority targets. Similarly, the total number of probe trials was divided equally across the four possible distractor groups (old majority, old minority, new majority, and new minority) and were generated on a random basis. The trial type (target search or probe detection) within each condition was fully randomized within blocks and block order was randomized across participants. A general block of practice trials for both the preview and the full-set baseline conditions was completed at the beginning of the experiment. None of these practice trials were included in the analysis.

Standard search trials took the following form. Each trial began with the presentation of a plain white fixation cross, which remained visible until the end of each trial. For both preview conditions this was followed by the presentation of the preview display (for either $150 \mathrm{~ms}$ or $1000 \mathrm{~ms}$ ). For both of these conditions participants were instructed to remain fixated and not to initiate search until the arrival of the second display (which always contained the target on the most frequent trial types). For these preview conditions, RTs were measured from the onset of the second display.

Luminance probe trials followed a similar procedure and were signaled by a $20 \mathrm{~ms}$ auditory beep of $1000 \mathrm{~Hz}$. The cue occurred $20 \mathrm{~ms}$ before the presentation of the second search set. Up until this point participants did not know the nature of the search task for that particular trial. Participants were instructed that, when the 
auditory cue occurred, the task was to locate, as quickly and as accurately as possible, the brightest letter on the screen (which could occur anywhere). The probe could fall on any of the four distractor letters (chosen randomly and counterbalanced), and it fell equally often on either a new or an old letter (randomly determined) and on any of the groups. Initial responses to probes were made by pressing the space bar upon locating the probe letter (these RTs were recorded for analysis). Upon locating the probe and pressing the space bar, the display was immediately cleared of all items; participants were presented with a new screen that asked "what was the brightest letter" and were given a reminder of the four possible options $(H, I, V$, or $X)$. Participants then typed the identity of the probed letter from the four possible distractor letters and their accuracy was recorded. The experiment lasted approximately $50 \mathrm{~min}$.

\section{Results}

The RT data for both target and probe-search trials were trimmed for outliers (deemed at $\pm 2.5 S D$ and any response faster than $200 \mathrm{~ms}$ ) and incorrect responses. Three participants were removed from the analysis for producing either excessively slow search $(>8000 \mathrm{~ms})$, high error rates $(>15 \%$ in any cell), or both. The formal analysis was carried out on the remaining 23 participants. The data for the search and probe trials were initially analyzed separately in one-way within-subjects analyses of variance (ANOVAs). These were further decomposed using a series of planned ANOVA comparisons.

Search trials. First, search RTs to targets carrying the minority or majority color in the second display were averaged for both conditions, to provide an overall RT for search in each condition. These data were then entered into a one-way ANOVA. This revealed a significant effect of preview duration, $F(1,22)=$ $18.276, p<.001$. Search was slowed when observers were given only a $150-\mathrm{ms}$ preview duration, relative to when there was a 1000-ms preview duration (a difference of $257 \mathrm{~ms}$ ). Search RTs were then separated as a function of whether the target appeared in the new majority or the new minority color for both conditions. These were then compared in a $2 \times 2$ (Preview Duration $\times$ Color Group) within-subjects ANOVA. This revealed significant main effects of preview duration, $F(1,22)=17.850, p<.001$, and color group, $F(1,22)=27.798, p<.001$. The Preview Duration $\times$ Color Group interaction was also significant, $F(1,22)=20.384$, $p<.001$ (see Figure 2).

The interaction was explored further by carrying out separate one-way ANOVAs on search RTs for targets from new minority and majority groups, for both preview conditions. There was no reliable effect of majority group when the preview was presented for $150 \mathrm{~ms}, F(1,22)=2.972, p=.100$. However, there was a large and significant effect of target group when the preview was $1000 \mathrm{~ms}, F(1,22)=37.696, p<.001$. When the preview duration was reduced to $150 \mathrm{~ms}$, target search overall was greatly slowed and any selective effect of whether the target belonged to a minority or majority color group was severely moderated.

Analysis of probe trials. To assess the effects on probe RTs, we evaluated probe performance in a $2 \times 2 \times 2$ (Preview Duration [1000 ms vs. $150 \mathrm{~ms}] \times$ Display [old vs. new] $\times$ Color Group [minority vs. majority]) within-subjects ANOVA. Neither the main effect of preview duration, $F(1,22)=1.434, p=.244$, nor

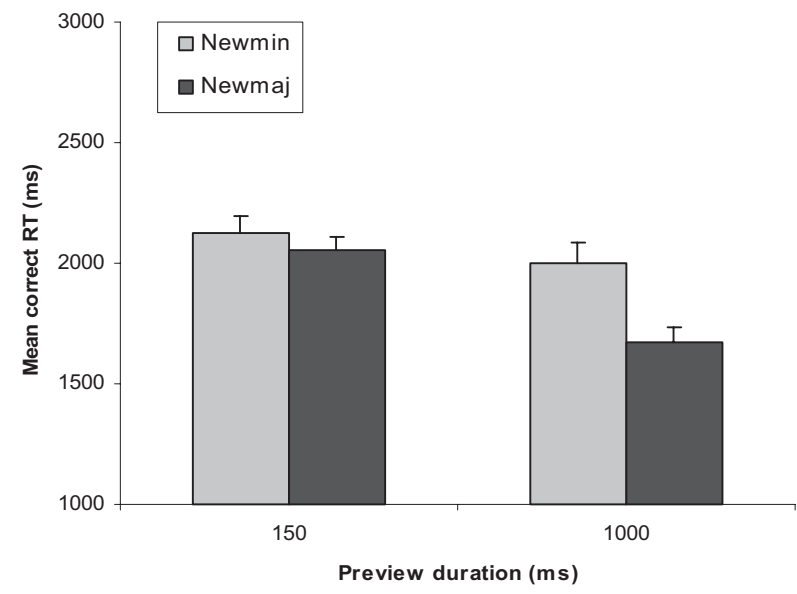

Figure 2. Mean ( $\pm S E$ ) target-letter search reaction times (RTs) as a function of whether the target had the minority $(33 \%)$ or the majority $(66 \%)$ color of the new search set (Experiment 1). Error bars represent standard error. Newmin = new minority; Newmaj $=$ new majority.

that of color group, $F(1,22)=2.235, p=.149$, was significant. There was a main effect of display (probe on old vs. probe on new), $F(1,22)=12.424, p<.01$. The interaction between preview duration and display was significant, $F(1,22)=4.892$, $p<.05$, as was the Preview Duration $\times$ Color Group interaction, $F(1,22)=6.553, p<.05$, and the Display $\times$ Color Group interaction, $F(1,22)=47.188, \mathrm{p}<.001$. The Preview Duration $\times$ Display $\times$ Color Group interaction was also significant, $F(1$, 22) $=10.118, p<.01, p<.05$.

RTs to probes were slower if they fell on old rather than new distractors, and performance varied according to whether the probe was an item in the minority or majority color group, in the old or new stimuli. The pattern of RTs when the probe fell in the majority relative to the minority color group changed according to whether the probe fell on a new or an old item. RTs to probes on old items were slowed if they were in the old majority color. However, RTs to probes on new items were slowed if they had the new minority color (i.e., carrying the color of the old majority). These effects of color increased as the probe duration increased (see Figure 3). Tables 1 and 2 display overall and individual means for probes falling on either an old or a new stimulus for each preview duration.

We explored these effects and interactions further by analyzing probe RTs as a function of color group for both old and new items separately. We carried out two separate $2 \times 2$ (Color Group $\times$ Time) within-subjects ANOVAs, one for probes falling on old items and one for probes falling on the new items. For probes falling on an old preview item this revealed significant main effects of color group and time, $F(1,22)=34.893, p<.001$, and $F(1,22)=4.635, p<.05$. The Color Group $\times$ Time interaction was not significant, $F(1,22)=1.342, p=.259$.

For probes falling on new items the main effect of time just failed to reach significance, $F(1,22)=3.280, p=.08$. The main effect of color group, $F(1,22)=15.426, p<.01$, and the Time $\times$ Color group interaction, $F(1,22)=8.775, p<.01$, however, were significant. For old items there was a trend for the effect of group to increase with time. For probes falling on new items this effect was much larger. 

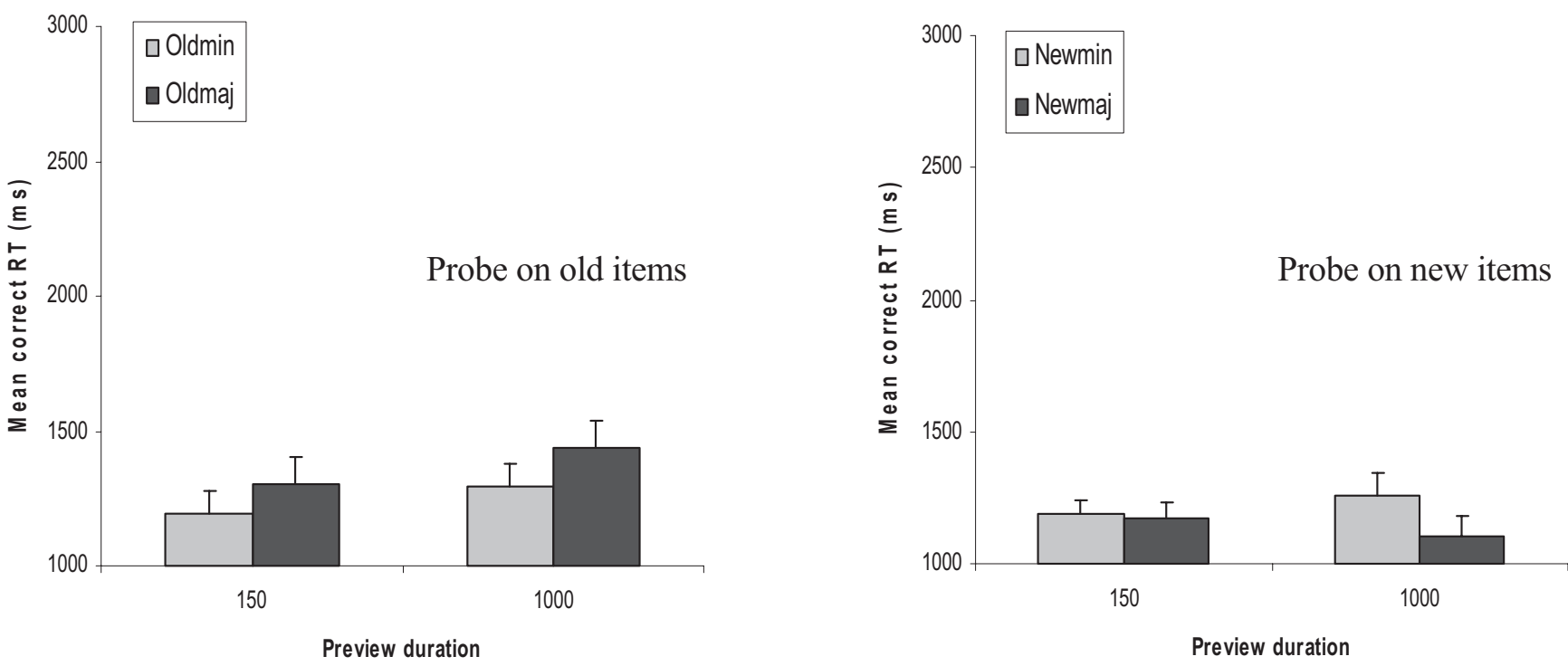

Figure 3. Mean ( $\pm S E$ ) reaction times (RTs) to probes on old or new items, as a function of whether they fell on a minority or a majority color in the old or new set (Experiment 1). Error bars represent standard error. Oldmin = old minority; Oldmaj = old majority; Newmin $=$ new minority; Newmaj $=$ new majority .

Errors. Error rates were low in all conditions. Overall, target search trials produced $4.87 \%$ errors. Probe-search trials produced $2.38 \%$ errors averaged across the conditions. Errors were averaged over old and new locations and entered into an overall $3 \times 2$ (Condition $\times$ Search Type) ANOVA. This revealed only a significant main effect of search type. There were more errors on search than on probe trials. The main effect of condition was not significant, nor was the Condition $\times$ Search Type interaction (all $F$ s $<$ 1 , all $p \mathrm{~s}>.05$ ). Like probe RTs, probe errors were also analyzed as a function of whether probes fell on old or new items and whether the items had the minority or majority color in their display. Although there was a trend for slightly more errors to probes in the new minority group, this was not significant. No other effects or interactions approached significance.

\section{Discussion}

Search RTs. The data on search trials replicate those reported by Braithwaite et al. (2003). RTs were overall faster when the preview duration was $1000 \mathrm{~ms}$ relative to when it was $150 \mathrm{~ms}$. This result in itself could be due to several factors, including an increased expectation for the new items or an

Table 1

Overall RTs for Probes Falling on Old or New Locations for Both the 1000-ms Preview Condition and the 150-ms Preview Condition in Experiment 1

\begin{tabular}{lccc}
\hline Condition & $\begin{array}{c}\text { Overall old } \\
\text { probe RT }\end{array}$ & $\begin{array}{c}\text { Overall new } \\
\text { probe RT }\end{array}$ & Difference (d) \\
\hline $1000 \mathrm{~ms}$ & 1370 & 1184 & 186 \\
$150 \mathrm{~ms}$ & 1250 & 1178 & 72 \\
Difference (d) & 120 & 6 & \\
\hline
\end{tabular}

Note. All values given in milliseconds. $\mathrm{RT}=$ reaction time. increased suppression of old items at the longer preview duration (Watson \& Humphreys, 1997). Moreover, there was a color carryover effect, which was increased at the long relative to the short preview duration (and it was not reliable with a $150 \mathrm{~ms}$ preview). Targets were easier to find when they had a new majority (old minority) color than when they had a new minority (old majority) color. In terms of just the new items, this effect is the opposite to that usually found in standard search, when all the items appear simultaneously (Bacon \& Egeth, 1997; Egeth et al., 1984; Kaptein et al., 1995; Moore \& Egeth, 1998; Poisson \& Wilkinson, 1992): Usually search is faster for targets in the minority color. This reversal of the standard effect is consistent with there being a negative color carryover, biasing search against the new items with the same color as the majority color in the preview. The evidence also indicates that this bias against the new minority (old majority) color increased at the longer preview duration. That is, the color carryover effect increased over time.

Probe RTs. On the whole, probe detection was much faster than target letter search, even though probe detection was only performed on a minority of trials. This is most likely due to the

Table 2

Overall Mean Differences between Old Minority Minus Old Majority and New Minority Minus New Majority Probe RTs in Experiment 1

\begin{tabular}{lccc}
\hline \multicolumn{1}{c}{ Condition } & Old maj - Old min & New min - New maj & $\begin{array}{c}\text { Difference } \\
\text { (d) }\end{array}$ \\
\hline $1000 \mathrm{~ms}$ & 145 & 155 & 10 \\
$150 \mathrm{~ms}$ & 112 & 20 & 92 \\
Difference (d) & 33 & 135 & \\
\hline
\end{tabular}

Note. All values given in milliseconds. RT $=$ reaction time; maj $=$ majority; $\min =$ minority. 
small luminance increment being more salient than the search target, which was matched in color and luminance to other letters in the display. Overall, RTs were also slower to probes on old compared to new items, and this was particularly the case with the longer preview duration. With a $150-\mathrm{ms}$ preview, RTs to probes on old items were on average $86 \mathrm{~ms}$ slower than those to probes on new items; with a 1000-ms preview this effect was 186 ms. The slow RTs to probes on old items could reflect an inhibitory bias against the preview (Watson \& Humphreys, 1997), or they could reflect attentional capture by the new stimuli (Donk \& Theeuwes, 2001). The increase in this effect at the longer duration is more consistent with an inhibitory bias, however, because $150 \mathrm{~ms}$ ought to be sufficient to enable the new items to attract attention (see Yantis, 1996, 1998, for reviews).

When probes fell on new distractors, performance was slower when they arrived in the new minority (same color as old majority) color than when they occurred in the new majority (same color as old minority) color. Like the effect on search, the bias against probes on letters with the new minority (old majority) color increased with time at the longer preview durations, and it was not reliable with a 150-ms preview. This negative color effect for probes on new items, like the color carryover effect on search, has a long time course.

When probes fell on old distractors, a quite different pattern of performance was apparent. First, probes were more difficult to detect when they appeared on items with the majority color. Second, a crucial new finding here was that this bias against the majority color was present with the $150-\mathrm{ms}$ as well as the $1000-\mathrm{ms}$ previews (although there was a trend for the magnitude of this effect to increase at the larger preview duration). This increase in the effect for probes on old items is consistent with the added presence of slower acting mechanisms biased against the old majority color, modulating the activations associated with the preview items. This study, then, provides the following evidence for distinct processes in preview search: (a) a fast-acting colorgrouping process, plus (b) a later process of negative color carryover. Color grouping is found with a short preview duration (measured by the probes to old items). The color carryover effect is found only at the long preview duration (measured by search targets and probes on new items). The fact that there was a large effect of color grouping in the preview display with a 150 -ms preview duration, while at the same duration color carryover effects are eliminated, suggests that current views of preview search need revising. We propose that, with a 150 -ms preview, there is an initial segmentation into minority and majority color groups, and an attentional bias is set towards the old minority group and/or attention is biased away from the old majority group (the color bias found under standard search conditions; Bacon \& Egeth, 1997; Egeth et al., 1984; Kaptein et al., 1995; Moore \& Egeth, 1998; Poisson \& Wilkinson, 1992). When the preview duration increased to $1000 \mathrm{~ms}$, additional inhibitory processes were directed towards the old items, based on the initial groups. This made probes on old items relatively more difficult to detect overall, and it increased the difference between probes on old items in minority and majority colors. In conjunction with this, a negative color carryover emerged for new targets and probes carrying the color of the majority old group. These additional effects of overall cost, of grouping cost in the preview, and the emergence of the carryover from preview to search items, are all predicted by the idea of slow-acting suppression of the majority color in the preview. These results are also difficult for alternative accounts of preview search to explain, a point we return to in the General Discussion.

The contrast between the carryover effects with 150-ms and 1000-ms previews also rules out an account of the color biases being due to targets in the new minority (old majority) color simply grouping with the old items (i.e., sinking into the background), because we would expect such grouping effects (if anything) to be larger with short relative to long duration previews. Other evidence against such a grouping account comes from Olivers and Humphreys (2003), who found color carryover effects even when previews disappeared at the onset of the new items (see also Braithwaite et al., 2004, for further evidence involving color changes).

In Experiment 2, we tested further whether the color bias effect, found with probes on preview stimuli, is itself modulated by the set to prioritize search to the new displays or whether it simply reflects the color properties of the displays. We used long duration previews (1000 ms) to maximize any bias against the old items. One condition mirrored the bias condition in Experiment 1: Participants searched for a new target on the majority of trials. However, unbeknownst to them, probes only ever appeared on old items. We refer to this as the probe-search condition. In a second condition, participants always attempted to detect a probe on an old item: the probe-only task. Because the displays were identical in the two conditions, an automatic carryover effect (perhaps governed only by grouping) should be the same. In contrast, the changed set in the probe-only condition, now to prioritize the old preview items, should remove any active suppression of those items. The color bias effect (against the old majority) should decrease accordingly.

\section{Experiment 2: Prioritizing Preview Items}

\section{Method}

Participants. Twenty-four participants (17 female, 7 male; 3 left-handed) took part for course credit or small payment. The age of participants ranged from 18 to 36 years with a mean age of 26.4 years. All were undergraduate or postgraduate students at the University of Birmingham. All had self-reported normal (including normal color vision) or corrected-to-normal vision.

Stimuli and apparatus. All the stimuli were similar to those used in Experiment 1.

Design and procedure. There were two preview conditions. One condition resembled the $1000-\mathrm{ms}$ preview condition from Experiment 1. There was a search task on the majority of trials in which participants looked for a target in the new search set $(66 \%$ of the time); on a minority of trials (33\%) they were then cued to discriminate a luminance increment added to one of the letters. The only difference, relative to Experiment 1, was that probes were only ever presented on old items (in the probe-search condition). Participants were not informed of this. In addition, a new condition was added that employed the same displays, but participants only had to carry out the probe detection task. In this probe-only condition, participants were told that probes would only fall on old items (rendering the old preview display as the relevant display) Hence, in this condition, observers should have had no incentive to suppress the old stimuli. 


\section{Results}

Target search RTs from the probe-search condition were analyzed in a one-way ANOVA with group (minority/majority) as the factor. This revealed a significant effect of group, $F(1,13)=$ 155.36, $p<.001$. RTs were, on average $367 \mathrm{~ms}$ slower for targets in the new minority (old majority) group relative to targets in the new majority (old minority) group. This replicates the search data from Experiment 1 (see Figure 4).

Probe RTs: Probe-search versus probe-only. A $2 \times 2$ withinsubjects ANOVA was calculated, with the factors condition (probe-search vs. probe-only) and group (probe in old minority or majority color). The main effects of condition and group were significant, $F(1,23)=5.38, p<.05$, and $F(1,23)=116.13, p<$ .001 , respectively. The Condition $\times$ Group interaction was also significant, $F(1,23)=21.10, p<.001$. Probes on old items were detected faster in the probe-only condition than when probe detection was embedded in the search task (the probe-search condition). Probes were also easier to detect when they fell in the minority color of the old items relative to the majority color. An interesting finding was that this effect of being in the old minority or majority group was much larger in the probe-search condition than in the probe-only condition. In the probe-search condition the mean difference between the groups was $248 \mathrm{~ms}, F(1,23)=$ $95.49, p<.001$. In the probe-only condition the mean difference was $45 \mathrm{~ms}$, which was not reliable, $F(1,23)=2.60, p=.120$ (see Figure 5).

Errors. Error rates were very low in all conditions. Target search trials produced an overall error rate of $6.10 \%$, and there was no significant effect of group, $F(1,23)=.67, p=.423$. The error rate on probe trials was $5.31 \%$. There were no significant main effects of either condition or group and no interactions (all $F_{\mathrm{S}}<$ 2.5 , and all $p \mathrm{~s}>1$ ).

\section{Discussion}

The results from Experiment 2 are clear. Target search RTs showed a large and significant effect of color with a preview duration of $1000 \mathrm{~ms}$. Targets that fell in the new minority color

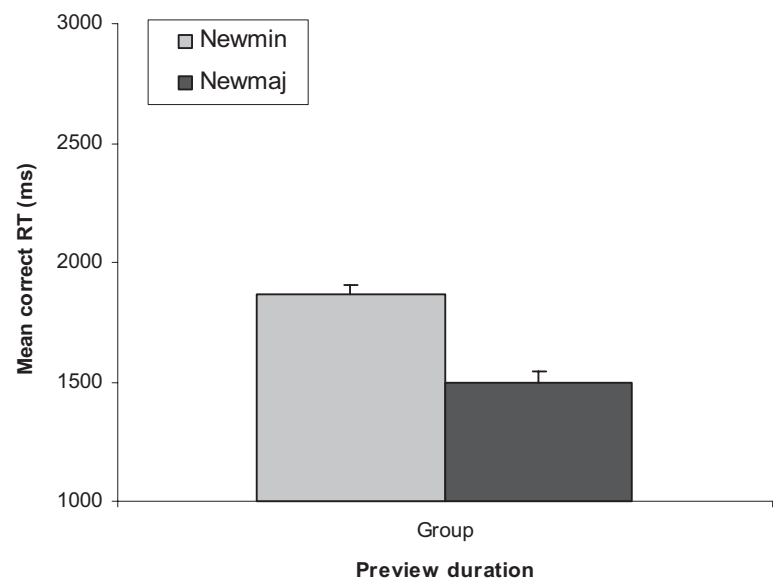

Figure 4. Overall mean $( \pm S E)$ correct search reaction time (RTs) in Experiment 2. Error bars represent standard error. Newmin $=$ new minority; Newmaj $=$ new majority.

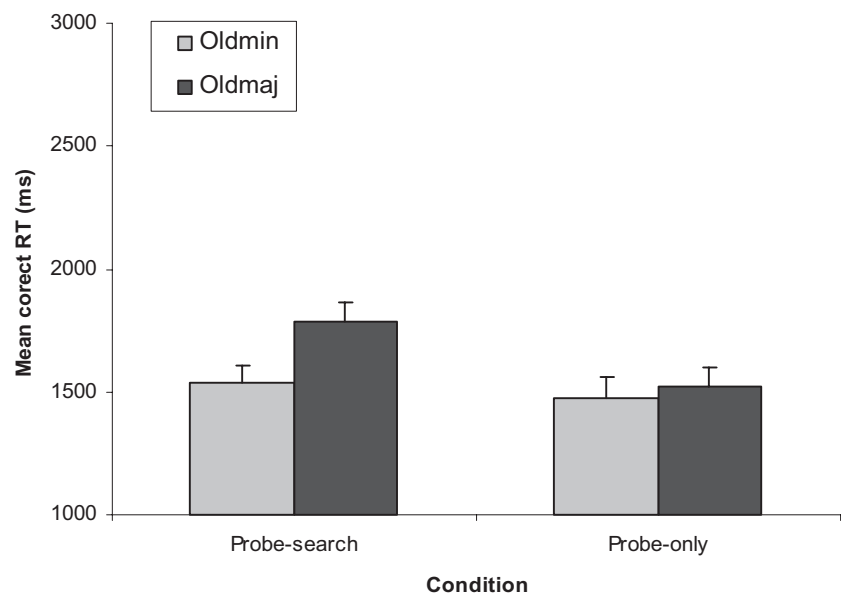

Figure 5. Mean ( $\pm S E$ ) correct reaction time (RTs) to probes in Experiment 2 (preview $=1000 \mathrm{~ms}$ ). Error bars represent standard error. Old$\min =$ old minority; Oldmaj $=$ old majority .

were slowed relative to when they fell in the new majority color (by approximately $370 \mathrm{~ms}$ ). This replicates the findings from Experiment 1 and is in line with previous research (Braithwaite et al., 2003; Braithwaite, Humphreys, \& Hulleman, 2005). More interesting are the data from the probe task. Probes on old items were detected most slowly when probe detection was the secondary task, in the probe-search relative to probe-only condition. This may reflect poorer performance in a secondary relative to primary task.

This is perfectly reasonable, as in the intermixed trial block there will have been an increased degree of uncertainty on any given trial as to which display was the relevant display (though the trial bias did induce an attentional bias towards the new items). This uncertainty would predict longer response times for probe RTs in the intermixed condition, relative to the condition in which only probe trials occurred.

In addition to this, the biases found on probes varied across the two conditions. This bias against probes on items in the old majority color was greater in the probe-search condition than in the probe-only condition. Most striking is the improvement in probe detection on old majority stimuli, when only probe detection took place. This suggests that prioritizing probe detection led to the bias against the old majority color being overridden, presenting a marked contrast to the case when search for new items was prioritized, in which there was an active bias against the old majority group (see also Experiment 4).

\section{Experiment 3: Suppression or Strategic Biases?}

From Experiments 1 and 2, we have argued that participants implement a bias against preview displays, with the bias being particularly strong against the majority group. The argument for this bias is drawn from the data on the detection of probes falling on old items. However, at least one other account of the probe detection data can be formulated. This is that performance is influenced by a form of a strategic bias sensitive to the item-byitem probability differences in the old preview display. For instance, in the experiments reported so far, an equal number of trials 
were dedicated to probes falling in the old minority and old majority groups. However, this meant that the probability of a probe falling on a given letter was less in the majority group. This might have biased participants against attending to the majority group. In prior studies we have assessed whether preview search was sensitive to such factors. For instance, Braithwaite and Humphreys (2003) altered the trial-by-trial probability of a new target carrying either the color of the old items or the color of the other new items. They found that search performance was relatively impervious to the manipulations of target probability, and, if anything, performance went in the opposite direction to that expected if observers were sensitive to the likelihood of the target being one of those items in a given color.

To test whether item-by-item probabilities were influential here, we manipulated the probability of a probe falling on items of a particular color. As in Experiment 2, we focused on any bias against the old majority color and so had probes appear only on old items. We also assessed performance with only the short prime duration from Experiment 1 (150 ms). In Experiment 2 we established that, with a prime duration of $1000 \mathrm{~ms}$, any bias against the old items was enhanced when probe detection was embedded in the search task. This enhanced bias against the old majority cannot be attributed to covariation in the probability of a probe appearing in a particular condition, because the probability was constant irrespective of whether or not the probe was embedded in search or whether it was the sole task. Nevertheless, the residual bias against the old majority group, present even with a $150 \mathrm{~ms}$ preview (Experiment 1), might reflect a small influence of the probability of the probe falling in the large versus the small group.

To test this, we examined performance here with a short prime duration $(150 \mathrm{~ms})$. We also tested performance when probe detection was the sole task. Under this condition we might expect to maximize differential sensitivity to the probability of the probe on a majority or minority group member. In addition, by only using a probe detection task, we assessed whether any bias to the minority group arose even when participants did not employ a set to search for the new items. As we have pointed out, previous studies have shown that the differential detection of probes on new compared with old items is reduced, and may even be eliminated, when only probe detection is performed. Here we ask whether the bias of attention due to color grouping arises even when there is no need to prioritize new items and whether this bias is the same size as when new items are prioritized for search (Experiment 1).

\section{Method}

Unless otherwise mentioned, the method was the same as in Experiment 2.

Participants. Twenty participants ( 12 female, 8 male; 1 lefthanded) took part for course credit or small payment. The age of participants ranged from 19 to 34 years with a mean age of 24.2 years. All were undergraduate or postgraduate students at the University of Birmingham. All had self-reported normal (including normal color vision) or corrected-to-normal vision.

Design and procedure. There were three preview conditions. In all cases, the preview duration was $150 \mathrm{~ms}$, only probe trials occurred, and probes only fell on the old preview items. Observers were told this. In one condition, the probes fell an equal number of times on stimuli in the old minority and old majority colors (the equal condition). In a second condition, probes fell on stimuli in the old minority group on $66 \%$ of the trials and in the old majority on $33 \%$ of the trials (the minority-bias condition). In the third, majority-bias condition, the probes fell on stimuli in the old minority group on $33 \%$ of the trials and on stimuli in the old majority group on $66 \%$ of the trials. All other procedures matched those outlined for earlier experiments.

\section{Results}

The mean correct RTs were analyzed in an overall $3 \times 2$ (Bias $\times$ Group) within-subjects ANOVA. This revealed only a main effect of group, $F(1,19)=62.95, p<.001$. Both the main effect of bias, $F(2,38)=.20, p=.822$, and the Bias $\times$ Group interaction were not significant, $F(2,38)=.64, p=.533$. RTs were slower to probes falling on old items in the old majority color relative to when they fell on items in the old minority color. This effect held across all the probability conditions, even when there was a trial-by-trial bias to the majority color (see Figure 6).

Errors. The overall error rate was low at $5.1 \%$, with the rates being $5.5 \%$ in the equal condition, $4.8 \%$ for the majority bias condition, and $4.9 \%$ for the minority bias condition. Errors were analyzed in the same manner as for RTs in a $3 \times 2$ (Bias $\times$ Group) within-subjects ANOVA. The main effect of group was just significant, $F(1,19)=4.75, p<.05$. The main effect of bias and the Bias $\times$ Group interaction were not significant (all $F \mathrm{~s}<1$, all $p$ s >.180). There were fewer errors for probes falling in the old minority group relative to the old majority group. This was the same for all conditions irrespective of probe probability. There was no evidence for a speed-accuracy trade-off.

\section{Discussion}

Experiment 3 assessed whether probe detection was biased by the probability that the probe fell on a letter in a given color group. We found that there was a bias in probe detection against the old majority group even when the probe was no more likely to be an individual letter in the old minority group than the majority group (and when it occurred more often in the majority color). Performance was also unaffected by varying the probability of which group the probe fell in. Thus, performance was relatively immune

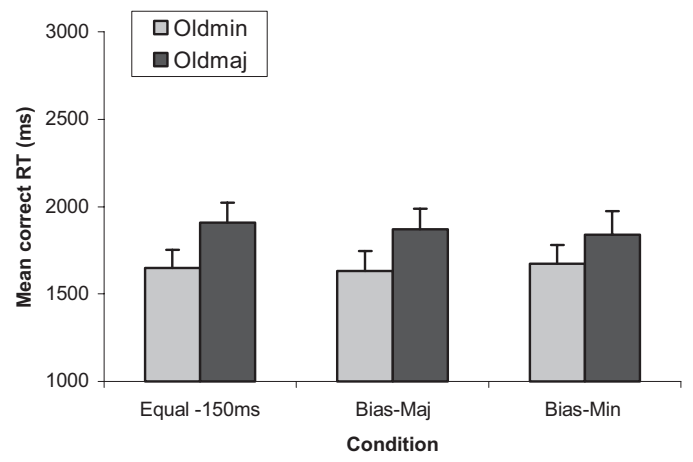

Figure 6. Mean $( \pm S E$ ) correct reaction times (RTs) to probes in Experiment 3 (preview $=150 \mathrm{~ms}$ ) for the three conditions: no bias (Equal), majority bias (Bias-Maj), and minority bias (Bias-Min). Error bars represent standard error. Oldmin = old minority; Oldmaj = old majority. 
to different strategies participants might adopt on the basis of the probabilities of the probe falling on majority and minority items. Therefore, we suggest that a probability-based strategy is not crucial for explaining the pattern of performance reported earlier in Experiments 1 and 2. In addition, the finding of a difference in probe detection across the majority and minority groups, with a preview duration of just $150 \mathrm{~ms}$, suggests that there is a rapidacting parsing process through which the preview is organized into two colored groups. An attentional bias then appears to be set against the majority group.

We find it interesting that the size of the bias to the minority group here (199 ms, averaged across the different probability conditions) was larger than the bias in Experiment 2, when participants performed only the probe task. The only difference between these conditions was in the duration of the preview prior to the probe occurring (long in Experiment 2, short in Experiment 3). This in turn suggests that any initial, perhaps automatic bias to the minority group either decreases or is overridden when the display is presented for longer and the task is to prioritize the probe (in the probe-only condition of Experiment 2). In contrast, this bias between the minority and majority groups in the preview is added to over time, when participants prioritize new items for search (e.g., in Experiment 1). We suggest that this reflects an active process of distractor suppression directed towards the old and irrelevant information, with the old majority group being subject to greater suppression (cf. Duncan \& Humphreys, 1989).

The findings from the previous experiments strongly suggest that color grouping and color inhibition enjoy distinct temporal profiles, with their impacts being separable to some degree. The lack of any feature-based carryover to new items, in addition to the strong effect of group on probes falling on the old preview display, is particularly revealing (Experiment 1). However, perhaps a more direct, clear, and unambiguous measure of the time course of color grouping would be to measure probe detection RTs as a function of preview duration under conditions in which observers had no intention to search for a target in the new set at all. ${ }^{2}$ In Experiment 1 , the new items were always relevant and all conditions contained both search and probe trials. In Experiment 2, we ran a condition that contained both search and probe trials and another condition that contained just probe trials alone (only at $1000 \mathrm{~ms}$ ). Experiment 3 tested for biases on old items but only at 150 -ms preview duration. To get a more comprehensive picture of the role of grouping over time, we ran similar conditions that compared 150-ms and 1000-ms preview conditions. Here in Experiment 4 we removed any intention to search for a target in the new display by having probes fall only on the old preview items, thus prioritizing the old preview display (and observers were made aware of this). This is important as it ought to remove the operation of colorbased inhibition, thus isolating the operation of the color-grouping process alone. The crucial difference here is that we directly compared grouping processes at both $1000 \mathrm{~ms}$ and $150 \mathrm{~ms}$, in the absence of color-based inhibition, within the same experiment.

\section{Experiment 4}

\section{Method}

Unless otherwise mentioned, the method was generally the same as described in previous experiments.
Participants. Twenty participants (16 female, 4 male; 1 lefthanded) took part for course credit or small payment. The age of participants ranged from 19 to 36 years with a mean age of 22.0 years. All were undergraduate or postgraduate students at the University of Birmingham. All had self-reported normal (including normal color vision) or corrected-to-normal vision.

Design and procedure. There were two preview conditions that shared the same displays as those described previously. Both conditions consisted of probe-only trials, in which the probe could only fall in the old preview items (either in the old minority group or old majority group, as with Experiments 2 and 3). However, here in the same experiment we ran a condition that employed a preview duration of $150 \mathrm{~ms}$ and another preview condition with a duration of $1000 \mathrm{~ms}$. Participants were told that probes would only fall on old items (rendering the old preview display as the relevant display) and that this would occur congruent with the presentation of the second display. Under these circumstances, observers should have no incentive to suppress the old stimuli. All other procedures matched that outlined for earlier experiments.

\section{Results}

Probe RTs in the 1000-ms preview condition were, on average, $625 \mathrm{~ms}$ faster relative to probe detection performance for the 150-ms preview condition. This difference was significant, $F(1$, $19)=120.70, p<.001$. This was further explored by conducting a $2 \times 2$ (Condition: $1000 \mathrm{~ms}$ vs. $150 \mathrm{~ms} \times$ Group: minority vs. majority) within-subjects ANOVA. Both main effects of condition and group were significant, $F(1,19)=97.18, p<.001$, and $F(1$, 19) $=67.30, p<.001$, respectively. The Condition $\times$ Group interaction was also significant, $F(1,19)=51.95, p<.001$. The effect of group was much greater at $150 \mathrm{~ms}$ relative to $150 \mathrm{~ms}$ (see Figure 7).

We further investigated this interaction by conducting one-way ANOVAs comparing probe RTs from minority and majority groups for each condition separately. With a preview duration of $150 \mathrm{~ms}$ there was a large and significant difference between probes falling in the two groups, $F(1,19)=69.195, p<.001$. Here probes falling in the minority group were detected faster than those falling in the majority group. In contrast, with a preview duration of $1000 \mathrm{~ms}$ this difference was greatly modulated and failed to reach significance, $F(1,19)=2.92, p=.104$.

Overall the error rate was low at $1.05 \%$. There were $1.15 \%$ errors in the $150-\mathrm{ms}$ condition relative to $0.95 \%$ at $1000 \mathrm{~ms}$. Errors followed the pattern of RTs and were compared in a $2 \times 2$ (Condition $\times$ Group) within-subjects ANOVA. This revealed no evidence of a speed-accuracy trade-off (all $F_{\mathrm{s}}<2$, and all $p \mathrm{~s}>$ $.240)$.

\section{Discussion}

With a preview duration of $150 \mathrm{~ms}$, there was a strong bias favoring probes falling in the old minority group relative to the old majority group. This replicates findings from Experiments 1 and 2 . As noted earlier, we suggest that this difference represents fast color-grouping processes parsing the preview display up into two

\footnotetext{
${ }^{2}$ We thank an anonymous reviewer for this suggestion.
} 


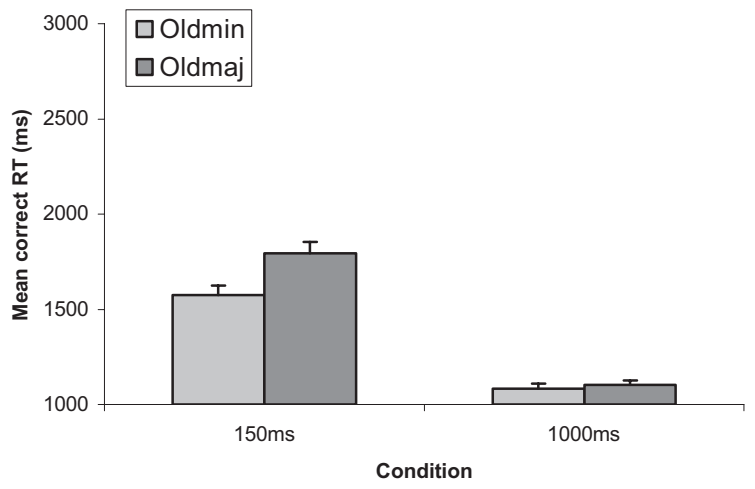

Figure 7. Mean ( $\pm S E$ ) correct reaction times (RTs) to probes falling on old items for both preview conditions at $1000 \mathrm{~ms}$ and $150 \mathrm{~ms}$ in Experiment 4. Error bars represent standard error. Oldmin = old minority; Oldmaj $=$ old majority.

discrete groups (a majority group and a minority group). When the preview duration was increased to $1000 \mathrm{~ms}$, this difference between the groups was greatly reduced. The resulting interaction, from a direct within-subjects comparison here, adds further weight that any initial bias to the old minority group either decreases over time or is overridden when the preview display is presented for an increased duration and the task is to prioritize the probe. The fact that both conditions only contained a probe falling in the old preview display means that the effects are unlikely to reflect any influences of negative bias such as color-based inhibition.

\section{General Discussion}

We have reported four experiments that employed a luminanceprobe technique to examine attentional allocation in preview search. The most important new result is the demonstration of a dissociation between two processes contributing to visual selection in preview search. One is a fast-acting color-grouping effect that operates on the preview items, parsing the display into minority and majority color groups. This process is quickly established and is in place by $150 \mathrm{~ms}$. Furthermore, the process is relatively immune to variations in the probability of where a probe will appear and its effect decreases or is overridden over time (at least when probe detection is carried out as the primary task).

In contrast, there is a separable process of negative color carryover when participants are engaged in preview search. This process is slower acting and is not observed with the brief preview duration (Experiment 1). The negative color carryover acts to bias search away from stimuli in the search display that carry feature values of old distractors that are deprioritized in search, with the bias being strongest for the stimuli associated with the greatest suppression (items carrying the feature values of the old majority group). Both the current and prior work indicates that this negative color carryover effect cannot simply be attributed to the new items grouping with the old distractors. If this were the case then one might expect that the carryover would be strongest when the effects of grouping were the strongest (i.e., at $150 \mathrm{~ms}$ ). Clearly this was not the case. In addition, Braithwaite, Humphreys, and Hulleman (2005) still found carryover effects when the old items changed color, thus removing the same-colored background pro- vided by the original preview display (see also Braithwaite et al., 2004). Here any grouping between the old and the new items should be greater with a short rather than a long preview, but color carryover effects were greater with long duration previews.

\section{Emerging Properties and Representations From Early Activation}

An important new finding in the present study is the strong effect of whether probes fell in the old majority or minority group with 150-ms previews, when, concurrently, there was no color carryover effect to new items. This indicates that distinct processes underlie the initial grouping process and the later inhibitory bias against old items. Previously, the negative color carryover effect has been attributed to a process such as color-map inhibition (Treisman \& Sato, 1990), in which the map for the color carried by the majority of preview items is suppressed (Braithwaite, Humphreys, \& Hulleman, 2005). The lack of color carryover with 150-ms previews, then, suggests that the effect of preview color on probe detection is not due to feature-map inhibition. We suggest instead that there is fast grouping and segmentation of the preview items into majority and minority color groups, and, at least for a short time afterwards, a bias for attention to be drawn to the old minority group (facilitating probe detection on these items). The grouping process itself may be thought of in at least two ways. One possibility is that members of the group are linked into a single perceptual structure and selected (or rejected) together as a common entity (Duncan \& Humphreys, 1989, 1992). This selection process may be biased to the smaller perceptual group. Alternatively, items having the same color may suppress one another by lateral inhibition (as in guided search; see Wolfe, 1994), so that items in the majority group are less activated (having more lateral inhibition) than members of the minority group. In either case, the net effect will be that members of the larger group tend not to be selected.

\section{Later-Acting Feature-Based Inhibitory Processing}

When participants prioritized new items for search, performance was improved with longer preview durations (for 1000-ms vs. 150-ms previews). This was matched by a slowing of RTs to probes falling on the preview, as the preview duration increased. In addition, there was a large negative color carryover effect on search, affecting both target detection and the detection of probes falling on new distractors carrying the color of the majority of items in the preview (Experiment 1). The color carryover effect was matched by an increase in the difference between RTs to probes on items in the old majority and old minority colors, as the preview duration lengthened. Taken together, these results are diagnostic of additional processes being recruited as the preview duration increased, which are linked to the intentions of the observer (e.g., occurring in the probe search but not the probe-only trials in Experiment 2) and which lead to an attentional bias against the old items in general and the majority color group in particular. We suggest that this is consistent with inhibition being applied in a top-down (intentional) fashion, against old items, in order to prioritize search to the new (Watson \& Humphreys, 1997).

Our findings also indicate that any inhibition of the preview items is based on their featural properties (their color) as well as 
their locations. This may operate via the direct inhibition of a color map activated by items in the preview (Treisman, 1999; Treisman \& Sato, 1990) — a process that may be computationally useful, as it would produce a global attenuation of activations associated with multiple distractors. Such a global attenuation process would, under most circumstances, increase the efficiency of selection in a limited capacity system.

However, one negative consequence of this would be a cost if new information carries the critical feature attribute of the old inhibited items. This is because activation associated with the new items would fall in a feature map already in a state of deprioritization. As long as the activation associated with these new items does not outweigh the level of inhibition currently within the system, then an inhibitory carryover will spread to the new items. Other evidence suggests that the negative carryover can be reduced or "reset" if the numbers of items with the critical color in the search display outnumber the same colored items in the preview display (Braithwaite et al., 2003). Thus, feature-based inhibition is dependent to some degree on the dynamic properties of the visual array over space and time (cf. Braithwaite \& Humphreys, 2003; Braithwaite, Humphreys, \& Hulleman, 2005; Watson \& Humphreys, 2002).

\section{Alternative Noninhibitory Accounts of Preview Search}

The present findings are particularly problematic for theories of preview search that do not assume active search biases, based on the properties of the old items. For instance, one account of preview search, put forward by Donk and Theeuwes (2001), is that the old items have a minimal impact on search because attention is captured by the new onsets of the search items. This account, however, has problems with several aspects of the current data. First, if there is attentional capture by new items, search should be biased to new stimuli in the minority color, because in "standard" displays there is a search advantage for targets in the minority group (Bacon \& Egeth, 1997; Egeth et al., 1984; Kaptein et al. 1995; Moore \& Egeth, 1998; Poisson \& Wilkinson, 1992). We found the opposite: Search is biased against stimuli in the new minority color, when this color is carried by the majority of items in the preview. We suggest that this reflects a negative color carryover effect from the old majority color. This result replicates prior findings from our laboratory (Braithwaite \& Humphreys, 2003; Braithwaite et al., 2003; Braithwaite, Humphreys, \& Hulleman, 2005).

Second, for an onset capture account, there is no reason to think that any bias away from the new minority color should increase with the preview duration, yet a trend for this pattern did occur here (Experiment 1). As long as the period between the presentation of both displays is sufficient to distinguish two separate events, then the new onsets should have an equal impact on search. In contrast to this, search suffered when the preview was reduced to $150 \mathrm{~ms}$.

Third, an account that attributes the preview benefit to the onset of the new items fails to explain why probe detection on old items slowed as the preview period increased from $150 \mathrm{~ms}$ to $1000 \mathrm{~ms}$. Finally, if capture alone were crucial, then differences in probe detection should not increase in the probe-search relative to the probe-only task (Experiment 2). However, these differences were greater with longer duration previews.
Another alternative account is that the preview benefit is due to the temporal segmentation of the old and new stimuli, which enables participants to select the new group without any effect of the old (Jiang, Marks, \& Chun, 2002). Unfortunately, this proposal encounters the same problems as the automatic onset account noted above, because temporal segmentation of the old and new displays should be completed even at the shortest preview duration used here (Yantis, 1996). The increases over time of the color carryover effects, and of color grouping on probe detection, are not predicted.

\section{Toward a Revised Functional Architecture of Inhibitory Filtering in Preview Search}

The present study demonstrates an important dissociation between different processes mediating preview search. These processes enjoy distinct temporal profiles-impacting on search either early on or after some time. With a short duration preview, the detection of probes falling on preview items is influenced by the grouping differences contained within that display-in the concurrent absence of any feature-based carryover to new items. This indicates that the early emerging minority and majority groups in the preview are formed prior to, and are not dependent on, the later acting inhibitory processes. These initial grouping processes appear to reflect fast-acting perceptual organizational mechanisms that may be independent of any intention by participants to ignore those items. Furthermore, when the preview duration was reduced to $150 \mathrm{~ms}$, RTs to new items increased overall and the selective impact from the color carryover to new items was abolished. We suggest that these two findings are linked. With a short preview, there is not sufficient time to effectively suppress members of each old group; the consequence is that old preview items still compete for selection, slowing search overall.

One account of the negative color carryover with longer duration previews is that it is based on the direct inhibition of a feature map for the color of the old distractors, with inhibition being greater for the majority group (cf. Treisman \& Sato, 1990). In a revision to feature integration theory, Treisman and Sato (1990) proposed that visual search could operate efficiently if participants could directly inhibit a whole "feature map" that was activated selectively by distractors. Here all activations coded within a particular feature dimension (such as a specific color) could be attenuated and inhibited en masse, thus making selection more efficient for a target carrying a different feature (see also Treisman, 1999). Unlike Watson and Humphreys (1997, 2000, 2002), we suggest that the mechanism of direct feature-map inhibition could help make static preview search faster and more efficient, complementing any location-based inhibition applied to old irrelevant distractors. There would certainly be computational advantages for a limited capacity system from coding multiple irrelevant items along a single dimension. However, the cost of this is that it is difficult to select new items that carry the same features (i.e., the same color) as the old stimuli. That is, the consequence of successful inhibition of the old items can lead to a negative featurebased carryover to new items. A negative effect would occur because there is an attenuation of any activation for same-colored new items because of their being registered in a system already in a state of deprioritization. Such inhibition would affect new items carrying the critical color value. 
The proposal for color as well as location-based inhibition contradicts the first account of preview search, put forward by Watson and Humphreys (1997). Watson and Humphreys (1997) proposed that new items were prioritized in preview search partly by inhibition being applied to the locations of the old items. Consistent with this location-based account are several findings, such as (a) there is poor detection of probes presented at old locations, (b) color differences are not necessary to generate a preview benefit, and (c) color changes in the old, irrelevant items do not impact the preview benefit (Humphreys et al., 2004; Olivers, Watson, \& Humphreys, 1999; Theeuwes, Kramer, \& Atchley, 1998; Watson \& Humphreys, 1997, 2000, 2002). However, it may be that the color-grouping effect that we have found with short preview durations is due not to the direct suppression of the color map but rather suppression of the locations of the old items guided by color. According to this "color-mediated location-based account," there is rapid color grouping of the items in the preview. This may then set up a bias that is based on the locations of the members of the minority and majority groups. This location-based bias (termed a "feature-guided" bias by Braithwaite et al., 2003) is added to, over time, by both location and feature-based inhibition, when participants prioritize the new stimuli in search. This magnifies the grouping effect at the long preview duration here (Experiment 1). Given the slow time course of the preview benefit in search (Watson \& Humphreys, 1997; see also Experiment 1 here), the processes of location and color-map inhibition appear to be slow and found only as the preview duration increases.

In sum, the present data provide further evidence that in preview search old items are encoded and their properties used to bias search towards the subsequent display. Our results also separate out two processes that influence this bias: (a) a fast-acting process based on segmenting the preview display into minority and majority color groups and (b) a slower acting process of color inhibition. Furthermore, although early color grouping is relatively immune to variations in a target color, it is added to by the set to prioritize search through a new display. By separating the processes of color grouping and color inhibition, the results also illustrate how preview search can be useful for fractionating basic mechanisms of search. Collectively, these findings show that preview search can be used effectively to investigate both early acting grouping processes as well as later additional inhibitory processes over time. Furthermore, we provide the first evidence yet that both processes contribute to preview search and enjoy distinct temporal profiles.

\section{References}

Agter, F., \& Donk, M. (2005). Prioritized selection in visual search through onset capture and color inhibition: Evidence from a probe-dot detection task. Journal of Experimental Psychology: Human Perception and Performance, 31, 722-730.

Bacon, W. F., \& Egeth, H. E. (1997). Goal-directed guidance of attention: Evidence from conjunctive visual search. Journal of Experimental Psychology: Human Perception and Performance, 23, 948-961.

Belopolsky, A. V., Peterson, M. S., \& Kramer, A. F. (2005). Visual search in temporally segregated displays: Converging operations in the study of the preview benefit. Cognitive Brain Research, 24, 453-466.

Braithwaite, J. J., Hulleman, J., Watson, D. G., \& Humphreys, G. W. (2006). Is it impossible to inhibit isoluminant items or does it simply take longer? Evidence from preview search. Perception \& Psychophysics, 68, 290-300.
Braithwaite, J. J., \& Humphreys, G. W. (2003). Inhibition and anticipation in visual search: Evidence from effects of color foreknowledge on preview search. Perception \& Psychophysics, 65, 213-237.

Braithwaite, J. J., Humphreys, G. W., \& Hodsoll, J. (2003). Color grouping in space and time: Evidence from negative color-based carry-over effects in preview search. Journal of Experimental Psychology: Human Perception and Performance, 29, 758-778.

Braithwaite, J. J., Humphreys, G. W., \& Hodsoll, J. (2004). Effects of colour on preview search: Anticipatory and inhibitory biases for colour. Spatial Vision, 17, 389-425.

Braithwaite, J. J., Humphreys, G. W., \& Hulleman, J. (2005). Color-based grouping and inhibition in visual search: Evidence from a probe detection analysis of preview search. Perception \& Psychophysics, 67, 81101.

Braithwaite, J. J., Humphreys, G. W., Watson, D. G., \& Hulleman, J. (2005). Revisiting preview search benefits at isoluminance: New onsets are not necessary for the preview advantage. Perception \& Psychophysics, 67, 1214-1228.

Donk, M., \& Theeuwes, J. (2001). Visual marking beside the mark: Prioritizing selection by abrupt onsets. Perception \& Psychophysics, 93, 891-900.

Donk, M., \& Theeuwes, J. (2003). Prioritizing selection of new elements: Bottom-up versus top-down control. Perception \& Psychophysics, 65, 1231-1242.

Donk, M., \& Verburg, R. C. (2004). Prioritizing new elements with a brief preview period: Evidence against visual marking. Psychonomic Bulletin \& Review, 11, 282-288.

Duncan, J., \& Humphreys, G. W. (1989). Visual search and stimulus similarity. Psychological Review, 96, 433-458.

Duncan, J., \& Humphreys, G. W. (1992). Beyond the search surface: Visual search and attentional engagement. Journal of Experimental Psychology: Human Perception and Performance, 18, 578-588.

Egeth, H. E., Virzi, R. A., \& Garbart, H. (1984). Searching for conjunctively defined targets. Journal of Experimental Psychology: Human Perception and Performance, 10, 32-39.

Humphreys, G. W., Jung-Stalmann, B., \& Olivers, C. N. L. (2004). An analysis of the time course of visual marking using a probe-dot procedure. Perception \& Psychophysics, 66, 713-730.

Humphreys, G. W., Olivers, C. N. L., \& Yoon, E. Y. (2006). An onset advantage without a preview benefit: Neuropsychological evidence separating onset and preview effects in search. Journal of Cognitive Neuroscience, 18, 110-120.

Humphreys, G. W., Watson, D. G., \& Jolicoeur, P. (2002). Fractionating visual marking: Dual-task decomposition of the marking state by timing and modality. Journal of Experimental Psychology: Human Perception and Performance, 28, 640-660.

Jiang, Y., Marks, L. E., \& Chun, M. M. (2002). Visual marking: Selective attention to asynchronous temporal groups. Journal of Experimental Psychology: Human Perception and Performance, 28, 717-730.

Kaptein, N. A., Theeuwes, J., \& van der Heijiden, A. H. C. (1995). Search for a conjunctively defined target can be selectively limited to a colordefined subset of elements. Journal of Experimental Psychology: Human Perception and Performance, 21, 1053-1069.

Moore, C. M., \& Egeth, H. (1998). How does feature-based attention affect visual processing? Journal of Experimental Psychology: Human Perception and Performance, 24, 1296-1310.

Olivers, C. N. L., \& Humphreys, G. W. (2002). When visual marking meets the attentional blink: More evidence for top-down, limited capacity inhibition. Journal of Experimental Psychology: Human Perception and Performance, 28, 22-42.

Olivers, C. N. L., \& Humphreys, G. W. (2003). Visual marking and singleton capture: Fractionating the unitary nature of visual selection. Cognitive Psychology, 47, 1-42.

Olivers, C. N. L., Humphreys, G. W., \& Braithwaite, J. J. (2006). The 
preview search task: Evidence for visual marking. Visual Cognition, 14, $716-735$.

Olivers, C. N. L., Humphreys, G. W., \& Braithwaite, J. J. (in press). Feature-based inhibitory carry-over effects from old to new. Visual Cognition.

Olivers, C. N. L., Watson, D. G., \& Humphreys, G. W. (1999). Visual marking of locations and feature maps: Evidence from within-dimension defined conjunctions. The Quarterly Journal of Experimental Psychology, 52A, 679-715.

Peterson, M. S., Belopolsky, A. V., \& Kramer, A. F. (2003). Contingent visual marking by transients. Perception \& Psychophysics, 65, 695-710.

Poisson, M. E., \& Wilkinson, F. (1992). Distractor ratio and grouping processes in visual search. Perception, 21, 21-38.

Theeuwes, J., Kramer, A. F., \& Atchley, P. (1998). Visual marking of old objects. Psychonomic Bulletin and Review, 5, 130-134.

Treisman, A. (1999). Feature binding, attention and object perception. In G. W. Humphreys, J. Duncan, \& A. Treisman (Eds.), Attention space and action: Studies in cognitive neuroscience (pp. 91-112). New York: Oxford University Press.

Treisman, A., \& Gelade, G. (1980). A feature integration theory of attention. Cognitive Psychology, 12, 97-136.

Treisman, A., \& Gormican, S. (1998). Feature analysis in early vision: Evidence from search asymmetries. Psychological Review, 95, 15-48.

Treisman, A., \& Sato, S. (1990). Conjunction search revisited. Journal of Experimental Psychology: Human Perception and Performance, 16, $459-478$

Watson, D. G., \& Humphreys, G. W. (1997). Visual marking: Prioritizing selection for new objects by top-down attentional inhibition of old objects. Psychological Review, 104, 90-122.
Watson, D. G., \& Humphreys, G. W. (2000). Visual marking: Evidence for inhibition using a probe-dot detection paradigm. Perception \& Psychophysics, 62, 471-481.

Watson, D. G., \& Humphreys, G. W. (2002). Visual marking and visual change. Journal of Experimental Psychology: Human Perception and Performance, 28, 379-395.

Watson, D. G., Humphreys, G. W., \& Olivers, C. N. L. (2003). Visual marking: Using time in visual selection. Trends in Cognitive Sciences, 7, $180-186$.

Wolfe, J. M. (1994). Guided search 2.0. A revised model of visual search. Psychonomic Bulletin \& Review, 1, 202-238.

Wolfe, J. M. (1998). Visual search. In H. Pashler (Ed.), Attention (pp. 13-73). London: University College London Press.

Yantis, S. (1996). Attentional capture in vision. In A. F. Kramer, M. G. H. Coles, \& G. D. Logan (Eds.), Converging operations in the study of visual selective attention (pp. 45-77). Washington, DC: American Psychological Association.

Yantis, S. (1998). Objects, attention and perceptual experience. In R. D. Wright (Ed.), Visual attention. Oxford, England: Oxford University Press.

Yantis, S., \& Jones, E. (1991). Mechanisms of attentional selection: Temporally modulated priority tags. Perception \& Psychophysics, 50, 166178.

Received July 15, 2005

Revision received September 11, 2006

Accepted September 25, 2006

\section{ORDER FORM}

Start my 2007 subscription to the Journal of

Experimental Psychology: Applied! ISSN:1076-898X

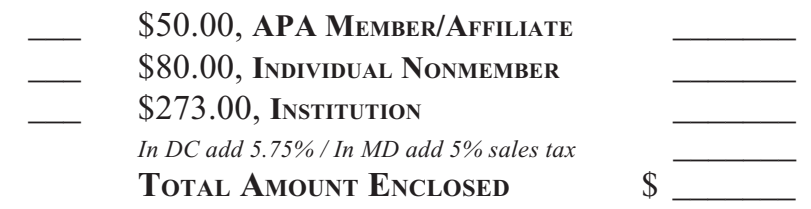

Subscription orders must be prepaid. (Subscriptions are on a calendar year basis only.) Allow 4-6 weeks for delivery of the first issue. Call for international subscription rates.

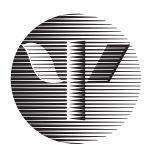

AMERICAN PSYCHOLOGICAL ASSOCIATION
SEND THIS ORDER FORM TO:

American Psychological Association

Subscriptions

750 First Street, NE

Washington, DC 20002-4242

Or call 800-374-2721, fax 202-336-5568

TDD/TTY 202-336-6123

For subscription information, e-mail: subscriptions@apa.org
Check enclosed (make payable to APA)

charge my: OVISA $\bigcirc$ MasterCard $\underset{\text { Express }}{\text { American }}$

Cardholder Name

Card No. _ Exp. Date

Signature (Required for Charge)

BILLING ADDRESS:

Street_
City State _ Zip
Daytime Phone $\_$
E-mail

MAIL TO:

Name

Address

$\begin{array}{ll}\text { City } & \text { State } \_ \text {Zip } \_ \text {XPA Member \# } \_ \text {XAPA7 }\end{array}$

